\title{
Reproducibility of solid-state fermentation at bench-scale: the case of protease production
}

\author{
Abraham J., Gea T., Komilis D.* and Sánchez A. \\ Composting Research Group, Department of Chemical, Biological and Environmental Engineering, Escola d'Enginyeria, Universitat Autònoma \\ de Barcelona, Bellaterra, Cerdanyola del Vallès, 08193 Barcelona, Spain \\ Received: 18/09/2016, Accepted: 13/12/2016, Available online: 03/05/2017 \\ *to whom all correspondence should be addressed: \\ e-mail: dkomilis@env.duth.gr
}

\begin{abstract}
Solid-state fermentation (SSF) process appears to be an efficient way to recover and valorise organic residues from industries and to generate other products of industrial significance, such as enzymes. As the reproducibility of SSF is one of the main drawbacks in the development of this process, a complete study on this point was carried out. Materials with high nitrogen content, soy waste (SW) and hair waste $(\mathrm{HW})$, were treated by SSF to obtain both proteases for different uses and a stabilized material for soil amendment. The bench scale reactors used in the experiments had a $4.5 \mathrm{~L}$ volume. Eight and five experiments were performed with the SW and $\mathrm{HW}$, respectively, over a period of 2.5 years with different batches of each material. The highest production of proteases was observed after 3 days and after 14 days of fermentation, for soy and hair wastes, respectively. In the case of hair waste (HW), the overall CV was close to $4.0 \%$ for both the maximum protease activity (PA) and the maximum specific protease activity (sPA). In the case of SW, the overall CVs recorded were $43 \%$ and $18.6 \%$ for the maximum PA and the maximum SPA, respectively. This demonstrates that SSF can be a reproducible process in bench scale reactors. This is the first study and a help to researchers to develop SSF experiments in a consistent and conclusive way.
\end{abstract}

Keywords: Solid-state fermentation; protease production; industrial organic wastes; reproducibility.

\section{Introduction}

The rapid development of the world population in modern societies has resulted in a significant increase in the production and consumption of a wide variety of materials. As a consequence, the use of natural resources and the generation of waste from different sources have continued to rise. Solid-state fermentation (SSF) is a three-phase heterogeneous process that involves a solid matrix, specifically the substrate, and it is performed in the absence or near absence of free water; however, the substrate must possess enough moisture to support the growth and metabolism of microorganisms (Mitchell et al., 1986) like in traditional composting. SSF is a promising biotechnology process that could be used as an alternative to submerged fermentation (SmF) for the production of different valued added products such as enzymes. Furthermore, several SSF experiments have demonstrated the production of several enzymes from different wastes (El-Bakry et al., 2015), indicating the possibility of valorisation of these residues and the consequent savings on natural resources. These materials, formerly considered wastes, can be used as resourceful substrates for microbial development and for the recovery of enzymes of biotechnological relevance (Rodriguez-Couto 2008; Zulkeflee et al., 2016). Enzymes are proteins with abilities in catalysis, being responsible for thousands of metabolic processes. Particularly, proteases have been used in a wide variety of applications in different industrial sectors and various household products. For instance, proteases can be used in detergent formulations (Paul et al., 2013), in food deproteinization (Valdez-Peña et al., 2010; Jellouli et al., 2011), in applications in pharmaceutical, paper and leather industries (Riffel et al., 2003; Kandansamy et al., 2012) and to enhance the availability of nutrients so that to increase soil fertility (Han and $\mathrm{He}, 2010)$. They can also be used in the synthesis of oligopeptides with specific functions (Qin et al., 2011; Viswanathan et al., 2012).

Although there is an increasing number of studies on SSF of wastes, the majority of them are performed with a few grams of materials at laboratory scale with the inoculation of specific microorganisms. Our research team has recently worked on the protease production from wastes at a benchscale using 4.5, 10 and $50 \mathrm{~L}$ reactors. The experiments were undertaken without sterilization of the substrates and by inoculating a microbial consortium that grows under a dynamic temperature profile including a thermophilic range similar to that of a composting process. Thus, this approach could pave the way to solve the constrains related to scale- 
up problems (Abraham et al., 2013; 2014; Maulini-Duran et al., 2015).

In the current study, two organic industrial residues with high nitrogen content, soy wastes (SW) and hair wastes (HW), were evaluated against the production of proteases by SSF at bench-scale static packed-bed reactors. Simultaneous replicates (obtained during the same experiment) and replicates taken at different times (different batches of the same material sampled at different time periods) were performed to assess the consistency (replication) and reproducibility of protease production. Because the residues were from different batches, individual characterization and characterization within the mixtures was performed each time. This was done since mixtures of solid residues are much more heterogeneous than the liquid media used during submerged fermentation (SmF).

Therefore, the objective of this work was to study how this heterogeneity influences the process and to evaluate how consistent SSF can be during bench-scale experiments performed with $4.5 \mathrm{~L}$ reactors. Parameters that indicate organic solids degradation, such as dry matter, as well as parameters indicating microbial activity, such as temperature, oxygen uptake rate (OUR) and the production of proteases were evaluated to obtain a profile for the SSF process. As the lack of information on this topic in scientific literature is evident, determining the conditions to have reliable, consistent and reproducible results is key for the success in future solid-state fermentation studies.

\section{Materials and Methods}

\subsection{Substrates}

Two different organic residues (wastes), with high content of nitrogen, were obtained from local industries to perform these experiments. The organic residues were:

- soy wastes (SW), which are generated during the production of soymilk and derivatives at food industry (Natursoy, Barcelona, Spain) as a result of the pressing of soy grains;

- hair wastes (HW), which are produced during the chemical leather dehairing process by the tanning industry under strong alkaline conditions (Igualadina de Depuració, Barcelona, Spain).

Both residues were mixed with bulking agent (wood chips) in a 1:1 ratio (w/w and $v / v$ for SW and HW respectively) to reduce the water content of the solid matrix and to provide the proper porosity for the subsequent SSF. Moreover, the hair waste, specifically, was mixed with raw sludge $(1: 2 \mathrm{w} / \mathrm{w})$ to adjust the $\mathrm{pH}$ of the initial mixture and to provide a source of microorganisms, as described in (Barrena et al., 2007). Addition of sludge was not necessary for the soy waste. Seven (7) and three (3) different samples of SW and HW, respectively, were received in different time periods. Each of those batches was characterized individually. Table 1 includes the range of values of the initial characterization of materials to illustrate the variability in the main parameters of the different batches. All experiments were performed over a period of 2.5 years.

\subsection{SSF process in bench scale experiments}

Mixtures weighing between 1.25 and $1.50 \mathrm{~kg}$ were fermented for 14 and 21 days in $4.5 \mathrm{~L}$ static packed-bed reactors that operated under near-adiabatic conditions (Abraham et al., 2013). Continuous aeration at a rate of $0.1 / \mathrm{min}^{-1}$ was provided into the reactors. Oxygen uptake rate (OUR) and temperature (T) were monitored online during the fermentation process. Grab samples from within each reactor were obtained at days $0,3,7,14$ and 21 of the process (at least in triplicates) after manual homogenization of the entire mass contained in each reactor. The experiments for each type of waste were undertaken in duplicates, triplicates or as simple runs without replication, depending on the goal of a given experiment and the availability of the material during the corresponding period. Experiments were labelled with the acronyms SW, for soy wastes, and HW, for hair wastes, followed by two numbers that indicated the trials (experiments) and the replicates (reactors) performed for each experiment. For example, SW1.1 and SW1.2 corresponded to the first and second simultaneous replicates (two reactors running at the same time) for the first experiment with soy waste. SW2.1, on the other hand, was the first replicate of the second SW experiment that was performed at a different time with a different batch taken from the same industry. On the other hand, SW4 indicates a single run (one reactor) without replication.

\subsection{Enzyme extraction}

The enzyme extraction was performed as described in Abraham et al. $(2013 ; 2014)$ and is briefly presented below. The fermented solid material was mixed thoroughly with 50 $\mathrm{mM} \mathrm{HCl}$-Tris (tris(hydroxymethyl)aminomethane) buffer $(\mathrm{pH}$ $8.10)$ at a ratio of $1: 5(\mathrm{w}: \mathrm{v})$ for $45 \mathrm{~min}$ and the extract was separated by centrifugation at $10,000 \mathrm{rpm}$ for $20 \mathrm{~min}$ at $4{ }^{\circ} \mathrm{C}$ with further filtration through $0.45 \mathrm{~mm}$ pore size filter. The filtered supernatant was used as crude enzyme extract for the determination of protease and soluble protein concentrations.

\subsection{Protease activity and soluble protein}

Protease activity (PA) was determined as described in Abraham et al. $(2013 ; 2014)$. One $\mathrm{mL}$ of the enzyme extract was added to $5 \mathrm{~mL}$ of $2 \%$ fresh casein solution and incubated at $50{ }^{\circ} \mathrm{C}$ and $100 \mathrm{rpm}$ for $2 \mathrm{~h}$. One unit of alkaline protease activity $(U)$ was defined as $1 \mu \mathrm{g}$ of tyrosine released per minute. The PA was expressed as $U$ per $g$ of dry matter of solid. Results are presented as mean \pm standard deviation from three replicates, whilst in two runs (SW1.2, SW3) only one enzyme activity measurement was performed. The soluble protein (SP) concentration was determined according to the method of Bradford using bovine serum albumin 
(Sigma Aldrich ${ }^{\circledR}$ ) as a standard (Bradford, 1976). The specific protease activity (SPA) was calculated as the ratio of enzymatic activity (i.e. PA) to the total amount of soluble proteins (SP) determined in the same extract.

\subsection{Degree of stability}

The dynamic respiration index (DRI) of the starting mixtures was measured via a dynamic respirometer described in detail in Ponsá et al. (2010). Briefly, $100 \mathrm{~g}$ of waste sample was placed in a $500 \mathrm{~mL}$ reactor. Each reactor (a $500 \mathrm{~mL}$ Erlenmeyer flask), contained a plastic net to support the organic waste and to provide an air distribution chamber and was placed in a water bath at $37^{\circ} \mathrm{C}$. Airflow in the reactors was adjusted by means of an air flow controller (BronkhorstHitec, The Netherlands). Air passed through a humidifier at the same temperature of the reactor to avoid water losses and moisture changes. Exhaust air from the reactors was sent to an oxygen sensor prior to dehumidification in a water trap made from an empty flask. DRI is expressed in mg of oxygen consumed per g of dry mass per hour ( $\mathrm{mg} \mathrm{O}_{2} \mathrm{~g}^{-1} \mathrm{DM} \mathrm{h} \mathrm{h}^{-1}$ ) and indicates the degree of stability of each sample.

\subsection{Standard analytical methods}

Dry matter (DM) was determined by gravimetric analysis after drying at a temperature of $105^{\circ} \mathrm{C}$ until constant weight. The organic matter (OM) content was determined from the loss on ignition at $550^{\circ} \mathrm{C}$ and the total Kjeldahl nitrogen (TKN) was determined by standard procedures according to Test Methods for the Examination of Composting and Compost (USDA and USCC, 2001). Crude protein content was estimated from the TKN content by multiplying by 6.25 .

\subsection{Statistical analysis}

All the enzyme activity results per sampling time and per reactor are expressed as the average \pm standard deviation from at least three replicates. When available, for each experiment (single reactor), a statistical comparison was performed using the triplicate measurements of enzyme activity. Comparison was performed with the Tukey's test at $p<0.05$. The grand mean from all experiments was calculated by accounting for only the replicates that were statistically equal (at $p<0.05$ ), according to the results of the aforementioned Tukey's test.

\section{Results}

\subsection{SSF of soy waste}

As shown in Table 1, the range of initial values for all soy waste batches was relatively narrow indicating similar initial properties among those batches of that waste. Only a notable difference was evidenced in $\mathrm{pH}$ (the low 5.4 value was considered a rather low extreme), which is explained by the variable storage times within the industrial site prior to delivery to the laboratory.

Table 1. Characterization of soy waste $(n=7)$ and hair waste $(n=3)$ as received from the industries.

\begin{tabular}{ccc}
\hline Parameters & Soy & Wair \\
\cline { 2 - 3 } & \multicolumn{2}{c}{ Hair } \\
\hline Water content $(\%, \mathrm{wb})$ & $80.4-83.0(82.5)$ & $59.9-71.4(65.1)$ \\
Organic matter $(\%, \mathrm{db})$ & $93.5-97.7(95.4)$ & $86.0-92.2(89.8)$ \\
$\mathrm{pH}$ & $5.4-7.4(6.7)$ & $9.8-10.8(10.2)$ \\
$\mathrm{EC}\left(\mathrm{mS} \mathrm{cm}^{-1}\right)$ & $0.7-0.9(0.8)$ & $5.0^{*}$ \\
Respiration index (DRI) $\left(\mathrm{g} \mathrm{O}_{2} \mathrm{~kg}^{-1} \mathrm{DM} \mathrm{h}^{-1}\right)$ & $4.5-5.6(4.9)$ & $3.0^{*}$ \\
Total Organic Carbon (\% db) & $67-71(68)$ & $45-57(51)$ \\
Total Kjeldahl Nitrogen (\% db) & $4.4-5.3(4.7)$ & $6.9-12(8.9)$ \\
C/N ratio & $13.5-15.4(14.4)$ & $4.8-6.5(5.7)$ \\
Fat content-HEM (\% db) & $5.3-7.6(6.9)$ & $0.9 *$ \\
\hline
\end{tabular}

Range of values measured from all batches throughout the whole experiment period; the value in parenthesis is the mean value; *Only one sample assayed $(n=1)$.

Table 2 shows the characterization of the initial mixture and selected parameters for eight soy waste experiments: maximum OUR, integrated area under the temperature curve (an ad-hoc coefficient that expresses the magnitude of the temperature) and the OUR curve (total amount of $\mathrm{O}_{2}$ consumed), dry mass reduction and protease activity. Figure 1 shows the temperature profile during the SSF of replicates SW1.1, SW1.2, SW4, SW5 and SW6. The SW2 runs were not included in Figure 1 because of technical problems to obtain data from the computer whilst SW3 was excluded due to the shorter process duration. Only the first 7 days of SSF, that coincided with the main degradation and production of proteases, were considered (and are illustrated in the graphs) to compare all the fermentations.

According to Figure 1, replicates SW1.1 and SW1.2 had similar profiles. However, some differences were found in the following experiments (SW4, SW5 and SW6), especially at the beginning of the fermentation. The replicates of SW1 did not have a lag phase while a lag phase was evidenced in SW5 and SW6 and a longer one in SW4. At the same time, SW4 and SW5 exhibited a lower temperature increase and consumption of oxygen (Table 2). In the case of SW3 the maximum temperature registered was around $65 \circ \mathrm{C}$ and no lag phase was observed. The above differences can be partly explained by the fact that the soy waste used in the 
experiments SW4, SW5 and SW6 was frozen when it arrived from the factory and until the reactors were available. This could be one possible explanation to differences in temperatures profiles. As a consequence of freezing and thawing this residue, losses of degradable compounds or reduction of the vitality of microbial communities could occur. For example, Pognani et al., (2012) had showed that the lag phase was significantly affected by freezing even for periods as short as one week. Pognani et al., (2012) had, however, proved that the biodegradability of wastes, as measured by the DRI, was not altered after freezing for one year. On the other hand, SW5 and SW6 showed a lower DRI, thus indicating the labile components of soy waste.

Regarding the protease activities (Table 2), values in the same order of magnitude were obtained. In most of the cases, the higher production of proteases was observed at the $3^{\text {rd }}$ day of SSF that coincided with the thermophilic peak. However, the highest activity detected in SW4 and SW6 was obtained after the thermophilic peak (7 days). The highest values of PA recorded were 328, 350 and $394 \mathrm{Ug}^{-1}$ DM for SW1.2, SW3 and SW1.1 respectively. Moreover, the SPA (Table 2) represents the quantity of protein extracted from the solid matrix that has protease activity. This parameter $\left(\mathrm{U} \mathrm{mg}^{-1}\right.$ soluble protein, $\mathrm{SP}$ ) together with the units of activity per quantity of residue $\left(\mathrm{U} \mathrm{g}^{-1} \mathrm{DM}\right)$ complements the results in terms of production and seems to be useful to compare extracts from different residues. SP also shows the selectivity of the extraction and was similar for all runs, except for SW4.

Although SW4 and SW5 observed a little higher moisture content than the rest of batches, no correlation was found between protease activity and moisture. Similarly, no correlation was found between protease activity and the DRI (measured in the $500 \mathrm{~mL}$ flasks) or the maximum OUR recorded in the $4.5 \mathrm{~L}$ reactors used for the fermentation experiments. Similarly, no correlation was observed between DRI and the maximum OUR, as opposed to the findings of Almeira et al. (2015).
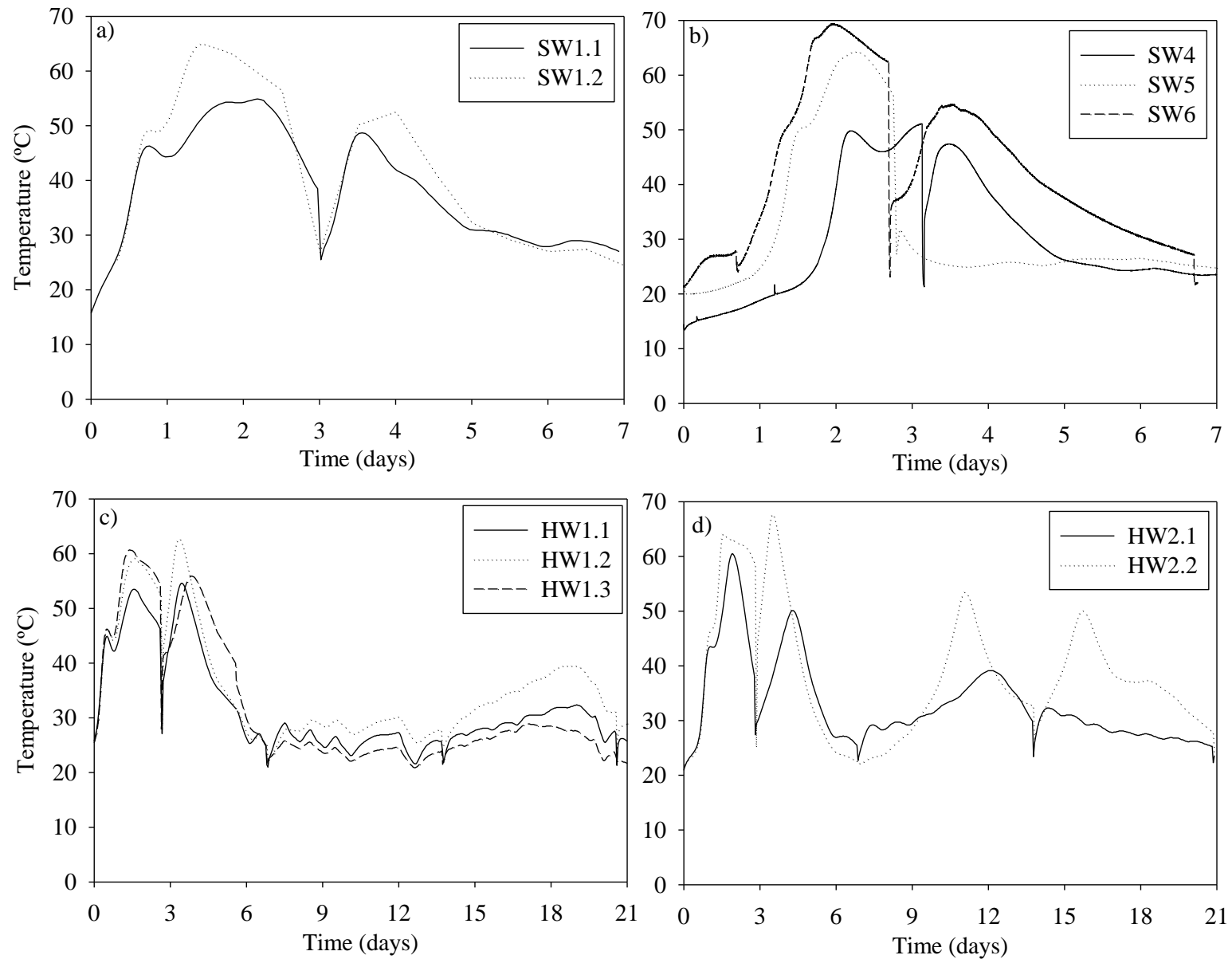

Figure 1. Temperature profiles obtained during the solid-state fermentation of a, b) soy waste for replicate runs SW1.1, 1.2, 4, 5 and 6 and c,d) hair waste for replicate runs HW1.1, 1.2, 1.3, HW2.1 and 2.2. 
Table 2. Characterization of initial mixture and process parameters obtained in the SSF of soybean and hair waste.

\begin{tabular}{|c|c|c|c|c|c|c|c|c|c|}
\hline Replicate & $\begin{array}{l}\text { Initial moisture of } \\
\text { mixture (\%) }\end{array}$ & $\begin{array}{c}\text { Bulk } \\
\text { density } \\
\left(\mathrm{kg} \mathrm{L}^{-1}\right)\end{array}$ & $\begin{array}{c}\text { DRI } \\
\left(\mathrm{g} \mathrm{O}_{2} \mathrm{~kg}^{-1} \mathrm{DM} \mathrm{h}^{-1}\right)\end{array}$ & $\begin{array}{c}\text { OUR max } \\
\left(\mathrm{g} \mathrm{O}_{2} \mathrm{~kg}^{-1} \mathrm{DM} \mathrm{h} \mathrm{h}^{-1}\right)\end{array}$ & $\begin{array}{c}\text { Area T } \\
\left({ }^{\circ} \mathrm{C} \text { day }\right)\end{array}$ & $\begin{array}{c}\text { Area OUR } \\
\left(\mathrm{g} \mathrm{O}_{2} \mathrm{~kg}^{-1} \mathrm{DM}\right)\end{array}$ & Dry mass reduction (\%) & $\begin{array}{c}\text { Max PA } \\
\left(\mathrm{U} \mathrm{g}^{-1} \mathrm{DM}\right) \\
3 \text { days } \\
\end{array}$ & 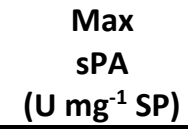 \\
\hline \multicolumn{10}{|c|}{ Solid-state fermentation of the mixtures of soy waste and bulking agent ( 7 days) } \\
\hline SW1.1 & 50.48 & 0.23 & $2.0 \pm 0.1$ & 1.69 & 271 & 142 & 13 & $400 \pm 15^{\mathrm{A}}$ & $61.3 \pm 1.5^{\mathrm{A}}$ \\
\hline SW1.2 ${ }^{+}$ & & & & 2.02 & 295 & 178 & 13 & 328 & 73 \\
\hline SW2.1 & 50.86 & 0.24 & $2.5 \pm 0.1$ & n.c. & n.c. & n.c. & 20 & $221 \pm 24^{B C}$ & $64.7 \pm 7.0^{A}$ \\
\hline SW2.2 & & & & n.c. & n.c. & n.c. & 20 & $160 \pm 18^{D}$ & $47.0 \pm 5.0^{\mathrm{B}}$ \\
\hline SW3 $^{+}$ & 49.7 & 0.23 & $2.3 \pm 0.1$ & 1.78 & n.c. & n.c. & 10 & 350 & 59 \\
\hline SW4 & 63.87 & 0.31 & $2.4 \pm 0.2$ & 1.45 & 212 & 68 & 14 & $229 \pm 3.3^{\mathrm{B} *}$ & $39.7 \pm 0.67^{B *}$ \\
\hline SW5 & 56.56 & 0.29 & $1.8 \pm 0.1$ & 0.90 & 224 & 65 & 12 & $101 \pm 1.1^{\mathrm{E}}$ & $66.0 \pm 1.0^{A}$ \\
\hline SW6 & 47.62 & 0.24 & $1.6 \pm 0.2$ & 2.23 & 289 & 149 & 11 & $184 \pm 6.7^{\mathrm{CD} *}$ & $61.3 \pm 2.5^{A *}$ \\
\hline Mean** & 53.18 & 0.26 & 2.11 & 1.68 & 257.9 & 120.5 & 14.1 & 228.0 & 58.0 \\
\hline$C V^{* *}$ & $11.3 \%$ & $13.4 \%$ & $17.1 \%$ & $27.8 \%$ & $14.7 \%$ & $42.3 \%$ & $27.1 \%$ & $43.0 \%$ & $18.6 \%$ \\
\hline \multicolumn{10}{|c|}{ Solid-state fermentation of the mixtures of hair waste and sludge with bulking agent (14 days) } \\
\hline HW1.1 & 44.7 & 0.32 & $1.3 \pm 0.2$ & 1.82 & 463.0 & 198.1 & 32 & $469 \pm 21^{\mathrm{A}}$ & $391 \pm 17.1^{\mathrm{A}}$ \\
\hline HW1.2 & & & & 2.29 & 504.6 & 199.4 & 37 & $501 \pm 21^{A}$ & $299 \pm 6.3^{B}$ \\
\hline HW1.3 & & & & 1.28 & 485.5 & 125.7 & 22 & n.a. & n.a. \\
\hline HW2.1 & 52.0 & 0.27 & $2.9 \pm 0.4$ & 1.74 & 497.7 & 132.8 & 23 & $486 \pm 8.0^{A *}$ & $312 \pm 5.1^{\mathrm{B} *}$ \\
\hline HW2.2 & & & & 1.43 & 545.8 & 127.7 & 21 & $395 \pm 20^{B}$ & $322 \pm 15.6^{B}$ \\
\hline Mean** & 48.4 & 0.30 & 2.10 & 1.71 & 499.3 & 156.71 & 27.0 & 485.0 & 311.0 \\
\hline$C V^{* *}$ & $10.6 \%$ & $12.0 \%$ & $53.9 \%$ & $22.9 \%$ & $6.10 \%$ & $24.53 \%$ & $26.3 \%$ & $3.8 \%$ & $4.2 \%$ \\
\hline
\end{tabular}

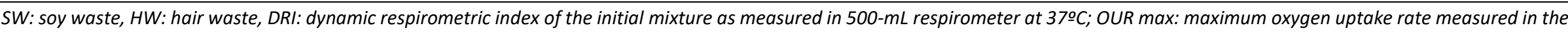

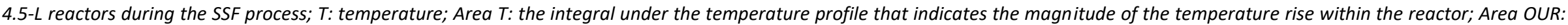

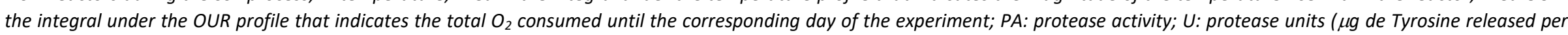
$\min ) ;$ SPA: specific protease activity; SP: soluble proteins; +: one measurement made $(n=1)$;

*: maximum value that was observed at 7 days of fermentation for these runs,

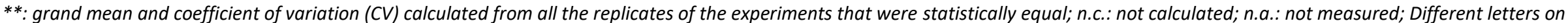
the same column indicate statistically different means at $p<0.05$ based on the analysis of variance test of Tukey. 


\subsection{SSF of hair waste}

As seen in Table 1, the initial properties of hair waste had a higher variability among batches than the initial properties of soy wastes. This was particularly true for TKN. However, the fermentations carried out with this residue had a similar temperature profile. Figures $1 \mathrm{c}$ and $1 \mathrm{~d}$ show the temperature measured during the 21 days of process from the replicates of the first (HW1.1, HW1.2 and HW1.3) and second experiment performed three months later (HW2.1 and HW2.2). In all the cases, temperatures reached thermophilic ranges after the first day of SSF and after almost four days at the thermophilic phase temperatures begun to descend. These temperature peaks coincided with the highest OURs, as expected. In addition, the oxygen content in the mixture never reduced below $5 \%(\mathrm{v} / \mathrm{v})$, in none of the cases, confirming the prevalence of aerobic conditions in all the experiments.

The extent of degradation was evident by the dry mass reduction in each reactor (Table 2 ). Figures $2 a$ and $2 b$ show the dry mass, organic mass and crude protein reduction at each sampling time for several $\mathrm{HW}$ replicates. In addition, the reduction in terms of crude protein is shown. A constant reduction of the $\mathrm{DM}, \mathrm{OM}$ and crude protein is observed until day 14 of the process, whilst no further reduction is observed thereafter. In the case of crude protein, the degradation process makes $\mathrm{N}$ available for protease production and releases volatile nitrogen compounds, such as ammonia. The gaseous emissions related to this mixture were determined by Maulini-Duran et al., (2015) and showed that significant amounts of ammonia were produced and emitted during the SSF of HW.

The results for protease activity demonstrated that the major activity was found at 14 days of fermentation in almost all individual replicates. Only HW2.1 had the maximum activity measured at 7 days (Table 2). The highest values recorded for HW were 394, 469 and $501 \mathrm{Ug}^{-1}$ DM for HW1.2, HW1.1 and HW3.1 respectively.
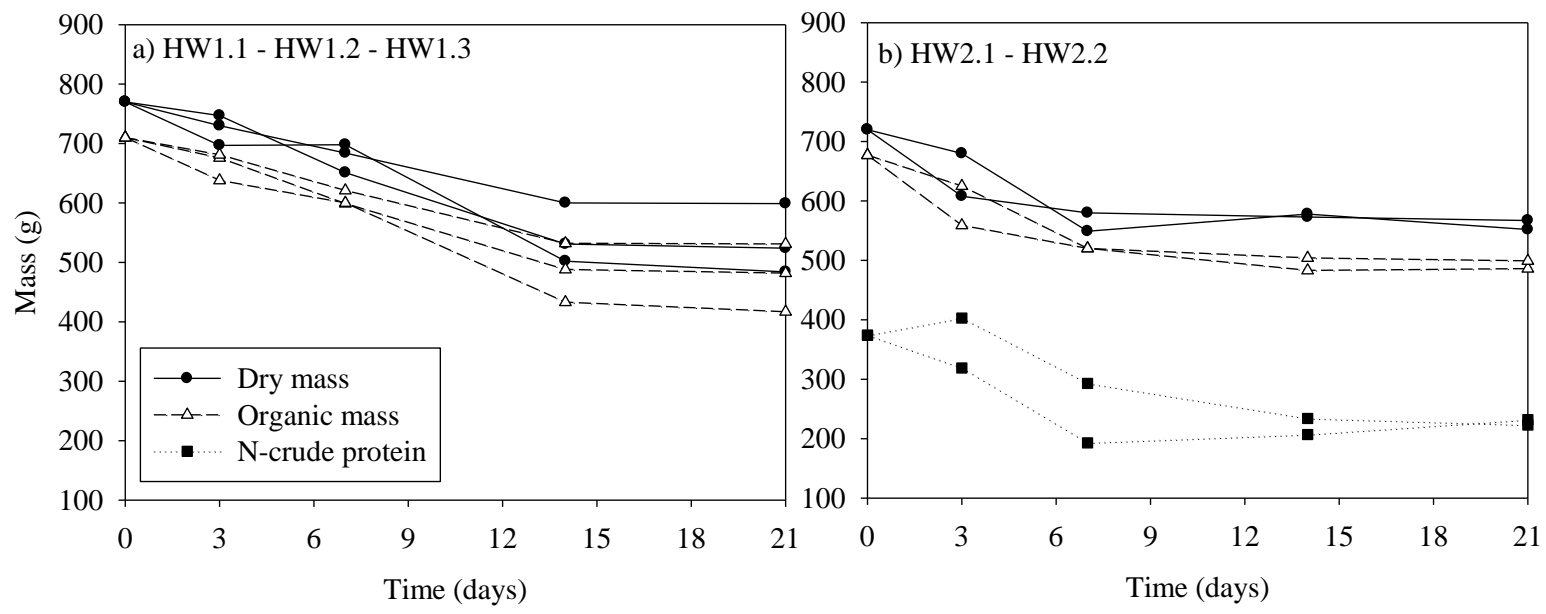

Figure 2. Mass reduction profiles obtained in the solid-state fermentation of hair waste for replicates a) HW1.1, 1.2, 1.3 (dry and organic mass) and b) HW2.1 and 2.2 (dry and organic mass and protein content).

\section{Discussion}

\subsection{Comparison between SW and HW fermentation profiles}

The differences between soy and hair waste fermentation profiles are related to the differences in the chemical composition, the biodegradabilities or/and the availability of nutrients of those substrates. Soy waste had $0.61 \mathrm{mg} \mathrm{mL}^{-1}$ of SP that gradually decreased to a final value of $0.18 \mathrm{mg} \mathrm{mL}^{-1}$ at day 14 . On the other hand, hair waste had a lower maximum value of SP equal to $0.26 \mathrm{mg} \mathrm{mL}^{-1}$ that stabilized to around $0.14 \mathrm{mg} \mathrm{mL}^{-1}$ from day 3 until day 21 . The soy waste's higher initial content of SP indicates the availability of the nutrients and the faster degradation that agrees with the higher biodegradability of that material and the maximum production of the proteases at the $3^{\text {rd }}$ day of SSF. On the other hand, the quantity of soluble proteins in HW was almost constant during the whole fermentation process. Although, HW had a higher $\mathrm{N}$ content, which was partially hydrolysed by the chemical treatment in the tannery, this nutrient is part of the structural protein of hair, namely keratin. Hence, it seemed to be degraded more slowly than the other materials and the main production of protease was detected on the $14^{\text {th }}$ day of SSF.

\subsection{Reproducibility of SSF measurements}

According to Figures 1 and 2, a clear consistency of the process is illustrated among the different experiments of each residue separately. For example, in all five runs of the soy waste, peak temperatures were reached at approximately the same time and were around $60 \circ \mathrm{C}$ to $70 \circ \mathrm{C}$ for four of the runs. Only the temperature of SW4 peaked at around 50 ㅇ. However, such small differences are expected 
for biological experiments with heterogeneous solid residues. Same observations can be made for the five HW runs that visually indicate the reproducibility of the experiments that were performed at different times over a period of 2.5 years and with different batches of the same waste.

At the same time, based on the statistics included in Table 2 (last two columns), it can be seen that three individual runs (reactors) from two separate batch experiments (i.e. HW1.1, HW1.2, HW2.1) provided statistically similar maximum protease activities. This is an important aspect in terms of the reproducibility of the results. The fact that the HW2.2 experiment provided (marginally) statistically different results from the other three runs is expected in biological experiments. Apart from the statistical similarity of the above-mentioned experiments, it is noted that the variance among the three internal replicates per experiment was rather low (a CV always less than 10\%) indicating that apart from the reproducibility, the replication of the experiments was also good. The overall CV of the grand mean (calculated from the three statistically similar experiments only) was $3.8 \%$ for the maximum PA and $4.2 \%$ for the maximum specific PA (sPA). It is noted that if all four HW are used to calculate the grand mean, the CVs become $9.6 \%$ and $11.6 \%$, respectively, which are still considered low values for biological experiments performed in the kilogram scale (with $4.5 \mathrm{~L}$ reactors).

In the case of SW, a similar low variability among the replicates of each experiment was calculated (the coefficients of variation among replicates were always lower than $5 \%$ ). On the other hand, a larger variability among the maximum PA values of the different experiments was observed in the case of SW, compared to $\mathrm{HW}$, as is evident in Table 2. The maximum PA grand mean for SW $\left(228.0 \mathrm{U} \mathrm{g}^{-1}\right.$ DM) had a CV of $43.0 \%$. This relatively large variability in the case of SW can be probably explained by the higher biodegradability of SW, compared to HW, and the freezing effect during storage as well as to the inherent variability of biological experiments. The different storage times of that waste (SW) within the factory can also explain that large CV for the maximum PA. The maximum SPA also had a larger variability (CV 18.6\%) compared to the sPA of HW (CV $4.2 \%$ ), but not as high as the variability observed for the maximum PA.

The aforementioned variabilities for both HW and SW cannot be considered high, if one accounts of the fact that these are biological experiments performed at a $4.5 \mathrm{~L}(1.5 \mathrm{~kg})$ bench scale; this indicates the consistency of the results at that scale. The fact that the HW results were less variable than the SW results (with regard to enzyme activity at least) might have to do with variations in the heterogeneities of the two substrates.

Several important issues regarding how to manage further SSF experiments can be deduced from this study. First, the variability (expressed as coefficient of variation) of the protease activity measured among batches from different experiments was less than $10 \%$ indicating the reproducibility of the results at a bench-scale. Anyway, the heterogeneity of the original material is crucial to achieve this reproducibility and consistency. In general, the results of this work confirm the possibility of using this low-cost SSF technology as a tool to valorise soy and hair wastes by obtaining proteases. The fact that the materials were real residues, without prior sterilization and without prior addition of a particular microorganism, suggests that the SSF process can be easily scaled up and reproduced.

\section{Acknowledgments}

Financial support was provided by the Spanish Ministerio de Economía y Competitividad (Project CTM2015-69513-R). J. Abraham thanks the financial support provided by $U A B$ for a pre-doctoral grant and Dr. Komilis thanks ACCIÓ for the financial support in UAB during 2014-2016.

\section{References}

Abraham J., Gea T. and Sánchez A. (2013), Potential of solid-state fermentation of soy fiber residues by native microbial populations for alkaline protease production at bench scale, Biochem. Eng. J., 74, 15-19.

Abraham J., Gea T. and Sánchez A. (2014), Substitution of chemical dehairing by proteases from solid-state fermentation of hair wastes. J. Clean Prod., 74, 191-198.

Almeira N., Komilis D., Barrena R., Gea T. and Sánchez A. (2015), The importance of aeration mode and flowrate in the determination of the biological activity and stability of organic wastes by respiration indices, Bioresource Technol., 196, 256-262.

Barrena R., Pagans E., Vázquez F., Artola A. and Sánchez A. (2007), Full-Scale Cocomposting of Hair Wastes from the Leather Manufacturing Industry and Sewage Sludge, Compost Sci. Util., 15, 16-21.

Bradford M.M. (1976), A rapid and sensitive for the quantitation of microgram quantities of protein utilizing the principle of protein-dye binding, Anal. Biochem., 72, 248-254.

El-Bakry M., Abraham J., Cerda A., Barrena R., Ponsá S., Gea T. and Sánchez A. (2015), From wastes to high value added products: Novel aspects of SSF in the production of enzymes, Crit. Rev. Env. Sci. Tec., 45, 1999-2042.

Han W. and He M. (2010), Short-term effects of exogenous protease application on soil fertility with rice straw incorporation, European Journal of Soil Biology, 46, 144-150.

Jellouli K., Ghorbel-Bellaaj O., Ayed H.B, Manni L., Agrebi R. and Nasri M. (2011), Alkaline protease from Bacillus licheniformis MP1: Purification, characterization and potential application as a detergent additive and for shrimp waste deproteinization. Process Biochemistry, 46, 1248-1256.

Kandasamy N., Velmurugan P., Sundarvel A., Raghava R.J., Bangaru C. and Palanisamy T. (2012), Eco-benign enzymatic dehairing of goatskins utilizing a protease from a Pseudomonas fluorescens species isolated from fish visceral waste, Journal of Cleaner Production, 25, 27-33.

Maulini-Duran C., Abraham J., Rodríguez-Pérez S., Cerda A., Jiménez-Peñalver P., Gea T., Barrena R., Artola A., Font X. and 
Sánchez A. (2015), Gaseous emissions during the solid state fermentation of different wastes for enzyme production at pilot scale, Bioresource Technol., 179, 211-218.

Mitchell D.A., Greenfield P.F. and Doelle H.W. (1986), A model substrate for solid-state fermentation, Biotechnol. Let., 8, 827-832.

Paul T., Das A., Mandal A., Halder S.K., Jana A., Maity C., Das Mohapatra P.K., Pati B.K. and Mondal K.C. (2013), An efficient cloth cleaning properties of a crude keratinase combined with detergent: towards industrial viewpoint, Journal of Cleaner Production, http://dx.doi.org/10.1016/j.jclepro.2013.10.054.

Pognani M., Barrena R., Font X. and Sánchez A. (2012), Effect of freezing time on the aerobic biological activity of organic solid waste, Bioresource Technology, 104, 832-836.

Ponsá S., Gea T. and Sánchez A. (2010), Different indices to express biodegradability in organic solid wastes, J. Environ. Qual., 39, 706-712.

Qin X., Xie W., Su Q., Du W. and Gross R.A. (2011), ProteaseCatalyzed Oligomerization of LLysine Ethyl Ester in Aqueous Solution, American Chemistry Society Catalysis, 1, 1022-1034.

Riffel A., Ortolan S. and Brandelli A. (2003), De-hairing activity of extracellular proteases produced by keratinolytic bacteria, Journal of Chemical Technology and Biotechnology, 78, 855-859.

Rodriguez-Couto S. (2008), Exploitation of biological wastes for the production of value-added products under solid-state fermentation conditions, Biotechnol. J., 3, 859-870.

The US Department of Agriculture and The US Composting Council, (2001), Test Methods for the Examination of Composting and Compost. Edaphos International, Houston, USA.

Valdez-Peña A.U., Espinosa-Perez J.D., Sandoval-Fabián G.C., Balagurusamy N., Hernández-Rivera A., De la Garza-Rodriguez I.M. and Contreras-Esquivel J.C. (2010), Screening of industrial enzymes for deproteinization of shrimp head for chitin recovery, Food Science and Biotechnology, 19, 553-557.

Viswanathan K., Omorebokhae R., Li G. and Gross R.A. (2010), Protease-Catalyzed Oligomerization of Hydrophobic Amino Acid Ethyl Esters in Homogeneous Reaction Media Using LPhenylalanine as a Model System, Biomacromolecules, 11, 2152-2160.

Zulkeflee Z., Shamsuddin Z.H., Aris A.Z., Yusoff M.K., Komilis D. and Sanchez A. (2016), Performance, yield and characteristics of bioflocculants (UPMBF13) produced by Bacillus subtilis UMPB13 during submerged and solid state fermentation, Global NEST Journal, 18, 611-620. 


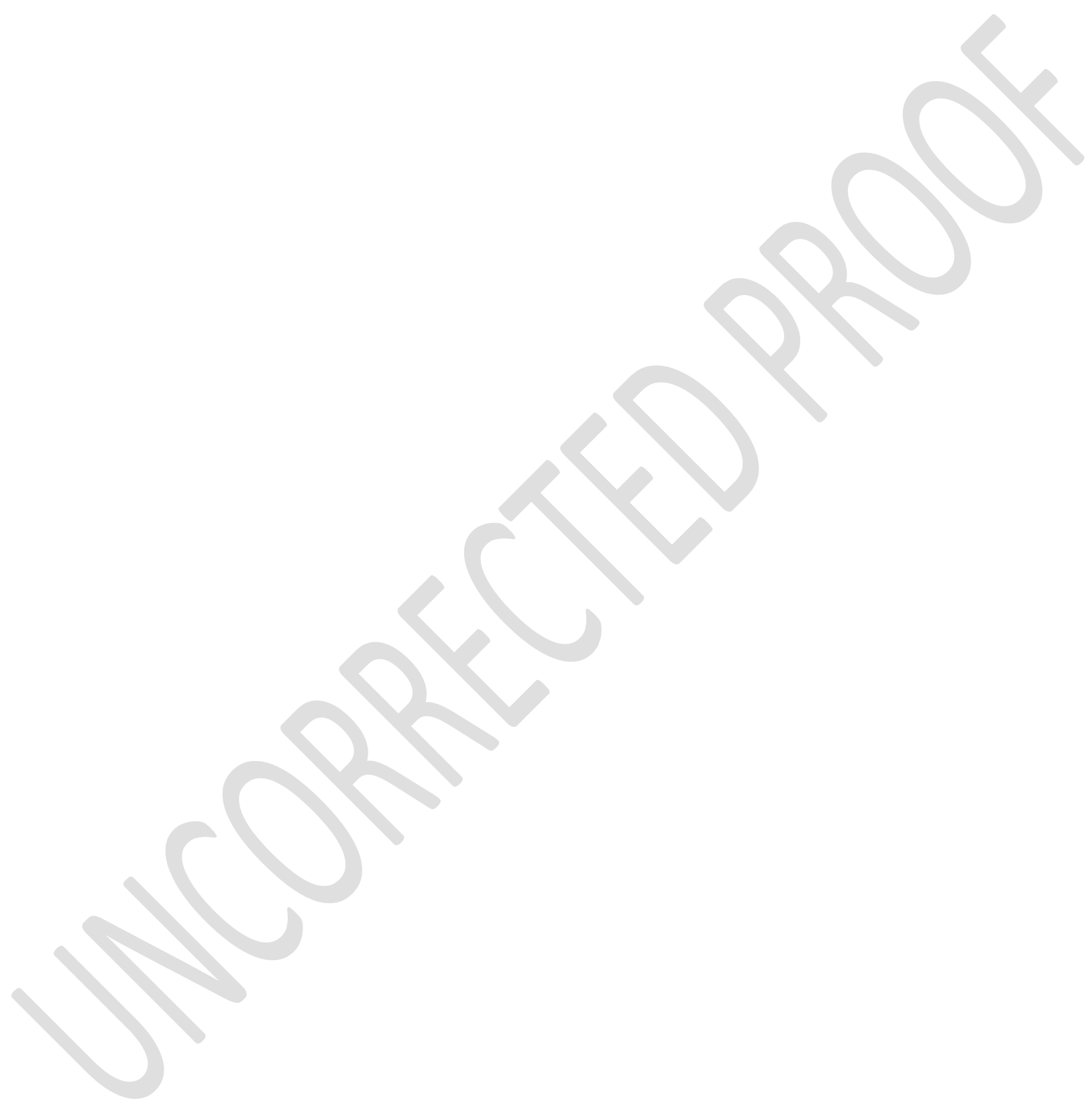

